\title{
Develop Critical Thinking by Classroom Activities
}

\author{
Hui Luan ${ }^{1}$, Lijing Jiang ${ }^{2}$ \\ ${ }^{1}$ Department of Accounting and Finance, University of Bangor, bangor, UK \\ ${ }^{2}$ Teacher Education College, Qufu Normal University, Shandong Province, China \\ luanlh605@hotmail.com,jiangjlj@163.com
}

\begin{abstract}
The goal of this paper has been to address the need for better answers to the question of what it means to be educated. Seeking answers to this question brings us back to the question, What should education accomplish? Consistent with the proposed objective of developing critical thinking as the best preparation for life, I propose two components as central to the definition of an educated person. One has to do with inquiry skills and the other with argument.
\end{abstract}

Index Terms - learn, critical thinking, inquiry skills, argument

\section{Introduction}

The answers to why we send our children to school are both straightforward and elusive. We want schools to prepare our children for life. We seek to produce students who will "love learning and value knowledge," who will become "confident and self-motivated learners" and "independent and responsible thinkers," who will be "open-minded and compassionate" and "fulfill their creative potential," who will display "curiosity, responsibility, self-assurance, independence and teamwork"-all of these are quotations from current brochures of premier public and independent schools. Or, put most simply in a report on the nation's middle schools, schools should help students "learn to use their minds well" [1]. However any sense of widespread agreement evaporates rapidly, as soon as we translate the abstract ideals of mission statements into the particulars of what children should spend their time doing in school. It is indeed very hard to move from this level of abstraction to a level even slightly more specific. Why is this so?

One answer is that modern society is changing so fast that we cannot imagine how our children will live in the future. We thus are not sure about how to prepare them for the adult lives and are able to identify educational objectives in only the broadest and most abstract of terms. Spokespeople from the vocational world, however, counter this view. They can tell us the skills they need their employees to have unhesitatingly, but lamenting that they so often find them missing. Employers say they are looking for "smart" employees who are able to adapt to new circumstances, assessing what they need to know and learning it, and who can engage in flexible teamwork to solve problems collaboratively[2].

Why haven't educators paid more attention to employers' voices identifying skills that will matter on the job? If we know that working as a member of a team to achieve a goal or solve a problem is a skill that students will need in their future lives, why wait until graduate school to introduce it? There are likely multiple answers to these questions, however, this paper will argue that we lack sufficient understanding of what it means to be an "independent learner and thinker" to make this an implementable goal in classrooms today.

Making more meaningful and realizable, the central objective of helping students learn to use their minds well is a purpose of this paper. But how do we justify developing the mind's capabilities, individually and in collaboration with others, as the major goal of education? The answer follows readily, if education is appropriately regarded as preparation for future life. From a societal perspective, the premise is that we should develop individuals who can function effectively in and contribute maximally to society. From a individual perspective, the justification is that developing the mind is the best possible preparation for the usually unpredictable demands and opportunities that life holds. To do so, we claim, they need to be able, individually and collectively, to seek knowledge to solve problems and to achieve goals, to argue reasonably to address issues and to make judgments, and to value these activities as the means to maximizing individual and social welfare. The core sets of intellectual skills they must develop to fulfill these individual and social objectives, I propose, are the skills of inquiry and of argument.

\section{Good Thinking}

Educating for thinking, the educational goal advocated in this paper, is no straightforward or small task. To begin to realize it, we must achieve greater clarity than exists now as to the path leading to good thinking, to minds being well used. We must indeed understand exactly what good thinking is, in the real-life contexts. In reaction to the objective, many educators may say, "We all know good thinking when we see it; let's not slow down trying to agree on definitions but proceed to concentrate on the more important, interesting challenge of designing the educational environments that will make it likely to appear." Given the prevalence of this stance, the educator today are more likely to agree on promising educational settings and activities for fostering thinking than on what the thinking skills are. In a word they may end up having much to say about how but relatively little about what, which is important for students to achieve.

Many people ask, "Don't we already know by now what critical thinking is?" What this paper brings to the debate is based on three characteristics distinguished from existing literature on thinking and education.

First, we have firmly based the paper's claims on empirical evidence. Second, this evidence is developmental in nature. We trace how the cognitive skills in question evolve from their initial emergent to their most highly evolved forms. 
Third, the paper situates thinking in contexts of students' current and prospective concerns and purposes beyond the classroom, with a focus on education for life. As a result, the concept of thinking skills adopted here contrasts sharply with the traditional one, which thinking skills are regarded as intellectual competencies that educators pursue instilling in students' heads so these competencies are available for use when needed. We insist thinking is something people do most often collaboratively, while they concentrate on accomplish the activities and goals during their daily lives. Thinking remains rarely a solitary activity conducted inside people's heads, but is most often a social activity embodied in the discourse that people engage in to advance their goals.

It is necessary to know fairly and precisely what a cognitive skill is, if educators hope to teach and develop it. Accordingly, we have devoted much of our research in the field of cognitive development to better understanding two major kinds of thinking skills, which we argue constitute a core of effective thinking. They are the skills of inquiry and argument, which are the topics of sections 3 and 4 of this paper.

\section{Inquiry}

\section{A. Learning to Learn}

Developing inquiry skills is not an educational mission we need to work hard to sell. Schools all want their students to acquire the skills equipping them to become independent learners, who are able to seek answers to their own questions. Education theorists are equally supportive of it as a core educational goal [3]. They claim that inquiry learning is superior to traditional instruction due to its involving students in authentic investigation of real phenomena, in the process fostering intellectual skills like those practiced by professional scientists in generating new knowledge. Growing enthusiasm for inquiry learning has paralleled the growth of the educational technology, in consequence, a wide variety of educational software and project based curricula designed to engage students in inquiry has been developed.

Inquiry curricula are not focused on the particular knowledge students may acquire but on teaching students how to inquire and learn. If accomplished, the outcome appears to be a powerful one, well worth the effort invested. Students become independent learners who take charge of their own learning, choose the questions they wish to investigate and seek and find answers to them.

Two characteristics are remarkable about the inquiry learning movement. First, it has been widely embraced. Just about everyone, such as education theorists, teachers, parents, even students, is enthusiastic about inquiry as a worthy educational activity. Almost any middle-school teacher will agree with the idea developing inquiry or "research" skills is important. Second, teachers have little to go on in striving to achieve these objectives. What, exactly, are the skills that need to be developed and how do teachers ensure their students are making progress toward acquiring them?

\section{B. Developing Inquiry Skills}

The context for the development of inquiry skills is a database of instances, usually accessed via computer. Students choose cases, working individually or collaboratively to examine with the goal of drawing conclusions regarding how the depicted factors relate to one another. In this case students have the freedom to direct their own investigations.

The structure underlying the database that students investigate consists of a network of causal relations. We reduce the initial level of complexity of this structure to a minimum based on the observations of the levels of skill that students bring to this activity. The five features introduced as potential causal agents in producing an outcome are dichotomous. In fact some of the features have no effect and others have simple additive effects on the outcome. Students are able to identify the causal and non-causal factors, if they conduct effective investigations, and to predict outcomes of specific feature constellations, which enable them to appreciate the value of their analytic efforts.

The goal of the inquiry experience is to promote the development of inquiry skills, not to teach science content. However it does not mean that the activity involves no meaningful content. Students bring a rich array of knowledge to their contemplation of the data presented to them for test. Though the structure of the causal relations reflected in these data is simple, students' ideas about them are not. We have found that omitting nonessential content from the available data enables student to concentrate on the processes by which one identifies, makes use of, and integrates new information.

One example of such an inquiry environment is the earthquake problem, in which students seek to identify the factors affecting earthquake risk. Although no direct instruction is provided, students are asked probing questions to promote reflection, for example "What do these results show?" and "What do you want to find out about?"

Students engage in the activity typically once or twice a week over a period of months. Microgenetic analysis tracks their changes that occur during this period of repeated engagement [4]. In this case dual forms of change are possible to be documented. The first is a student's increasing understanding of the causal structure underlying the database of observations. The second change is advances in the investigative and inference strategies one student uses to generate this knowledge [5].

We have now explored a number of different content domains in which to situate the activity. Interestingly, middleschool students find most appealing those topics having to do with everyday phenomena such as the features of TV shows. Thinking about such topics is easy and enjoyable to them, while it's not to think about more "scientific" topics in natural science domains, which they typically bring less well-formed ideas. In contrast, we have found, teachers are much more comfortable with more traditional science topics. With this discovery we have driven more frequent use of mainstream science content such as earthquakes and avalanches, and less typical content like TV shows and music clubs as well. 
My colleagues and I have found an association between the intention to identify the effect of an individual feature and the use of comparison as an investigative strategy, based on studies of students' working on the earthquake and other problems.

This may be so because both are supported by a mature additive mental model of causality. Unlikely is the goal to be identification of the effect of each of the individual features, in the absence of this model, to determine their cumulative effects. Neither attribute of a controlled comparison strategy, moreover, is likely to be considered as important. With its purpose to evaluate the effect of individual variables, the "comparison" attribute is not compelling. And because it is the individual effects of other variables which need to be controlled, the "controlled" attribute is even less compelling. Then an immature mental model of causality limits adoption of either the strategies or goals making for effective inquiry.

How does development of these strategies and goals occur? Our microgenetic studies indicate that, the opportunity to engage frequently in inquiry activity, in many, although not all, cases, is sufficient to promote change. Moreover, these studies have given us an opportunity to observe something about the manner which this development occurs in. The case study of Rose, who is a student at the best-practice school, is a good illustration, although not atypical. She made striking progress, especially because she was several years younger than Tom, Peter and Mark and only a fourth grader. Not unlike that of the three boys, she began at a developmental level in the course of several months of focused inquiry activity. And yet, she made a rapid progress to a moderately skilled level of inquiry.

The inquiry contexts described in this papter lack all of these forms of structural complexity. Neither do they undertake to improve students' scientific understanding of particular phenomena within either the physical or social world. Nor do they fit into any curriculum subject area. Nonetheless, I claim that it's worthy both for students engaging in and for educators making careful examinations. However, in the contexts, Students are not taught strategies or rules of how to conduct inquiry, but guided in the very simple practice of it, allowing students to gain their own sense of the power it affords and take charge of their own learning.

Educators usually see one of their core roles as helping students to obtain broader and deeper understandings about the physical and social world around them. To achieve this goal, however, their capacity to develop students' skills of inquiry is urgently needed. In doing so, devising circumstances to foster inquiry learning is at least as important as an educational goal.

\section{Argument}

\section{A. What is Argument}

Just about everyone such as education theorists, teachers, parents, even students are enthusiastic about inquiry as a valuable educational activity. Becoming an independent learner is a charming objective hard to be against. Argument, however, doesn't get the same immediately enthusiastic reception. Compared with the inquiry, which yields new knowledge and new understanding, the fruits of argument are less apparent. Its value is less clear.

Most middle-school and high-school teachers do say that they recognize the importance of argument and provide frequent opportunities for student debate in their classrooms. Yet they have even less to turn to in the way of resources than do teachers wanting to promote inquiry. Teachers are largely on their own in planning ways to foster discussion, to assess whether the debates occurring in their classrooms are productive, and, if not, to figure out how to improve it.And, as high-stakes tests perform an ever-increasing role in evaluating student outcomes, they are not certain how much time they should be devoting to it.

Nor is it clear what counts as argument. People may feel that argument is fine as long as it supports conclusions they like. Otherwise, truth is generally something's gone wrong and it's not to be trusted. Do we want students to become skilled and authentic debater whose outcome is not known in advance?

In fact, Argument assumes two forms. The first is an interior, individual form when a student engages in the process of arguing with oneself or formulates a line of reasoning to support a claim. The second form is exterior and social, as when two or more students argue with each other. These two distinct forms are closely related and entail a similar set of skills[6].

Developing skills of argument is, like inquiry, valuable education for life. What students need is not only to argue but also to argue well. Argument has the virtue of revealing its power and value in the process of being practiced just like inquiry. However, as we shall see, unlike inquiry, it has the advantage of its roots in everyday conversation.

\section{B. Developing Argument Skills}

How to develop argument skills? Different people have different views. In our opinions, dialogic argument provides the most productive context in which to promote argument skills.

Dialogic argument builds on the familiar activity of everyday conversation. The format is well known and practiced in everyday life. I pay attention to what you are saying to me, and try to make meaning from it. While awaiting a cue that you have finished speaking, I start to formulate a response that addresses what you have said, and expect that once I start speaking, you will do the same. In this way, two students' actions relate to one another, with one person's actions shaping those of the other.

If educators ask two students to begin a serious discussion, they build on this foundation of everyday conversation. Students show at least some degree of skill in such discussions. They can express their respective views and acknowledge their disagreements. We saw one partner may even scaffold the other's articulation of a position with probing questions. Yet going further, one partner requires more skill and understanding than the practice of everyday conversation to jointly construct a productive dialogic argument. 
Participants in dialogic argument need cognitive skills, by which to select the most effective response once they have digested their partner's contribution, and then as long as the dialog lasts, to do so again and again. This process is cognitively demanding. So participants in a dialogic argument need forming some understanding of its purpose, if they are to be disposed to invest the considerable effort that is required.

Why argue? What are we trying to achieve? Can we want to construct an argument, which will be more than the juxtaposition of our two positions? In doing so, what will we acquire? Can we want to accomplish anything more than agreeing to disagree?

They need a provisional answer to these questions at least. If all truths are out in the world awaiting discovery, as the absolutist sees it, or as the multiplist maintains, if there is no truth beyond individual predilection, there is indeed no point to argument. It does not pay to invest the cognitive effort required. Educators can ask such students to engage in dialogic argument and they will oblige. They, however, will be doing little more than going through a routine whose purpose they do not appreciate.

Although most middle- and high-school teachers say they try to make time for student debate, authentic dialogic argument is indeed difficult to accomplish in classrooms-in advantaged schools like the best-practice school, in disadvantaged schools as the struggling school, and most likely in the vast majority of schools between these extremes. Mrs. A at the best-practice school had students prepare by writing essays listing reasons for their positions, which they then presented in the argument. Ms. $\mathrm{H}$ at the struggling school encouraged a more explicit but similar form of preparation. Despite many differences in the abilities and experiences of the two groups of students, the outcome was largely the same. Both students at two schools rarely spoke directly to one another when presenting their prepared material.

Neither the form of the discussion in both classrooms, nor the topic drew on the resemblance between argumentive discourse and everyday conversation. Students at these schools accepted the activity as one of the many expected of them as part of their school life. Students, at the best-practice school, understood the primary purpose of the activity as helping them to acquire the information, which they would soon be tested on. At the struggling school, students had long ceased asking themselves what the goal was of any of the things they were obtained to do at school and they simply drew what enjoyment they could from the activities.

Although few educators quarrel with the idea of promoting students' thinking skills, they embrace many other goals, both curricular and extracurricular. Yet it is a challenge to do everything to a middle-school student. We saw that not a minute of students' time is wasted at the best-practice school, teachers in the different subject areas competing for a greater piece of the students' school day "pie". At the struggling school, Students, in contrast, spend too much time doing nothing; but even so, their school day is divided into many short blocks of time, during which students must shift locations and attention frequently and rapidly. The fact is that not all classes meet every day, at both schools, and some may meet as infrequently as twice a week or even longer. Students have little opportunity to get deeply involved in any activity, in both classrooms, over a sustained period, only with the possible exception of sports teams at the best-practice school. So continuing and integrating the curriculum are major matters of primary concern to contemporary curriculum specialists. The objective is a hidden or seamless curriculum, with links in place at every intersection and in two directions, vertically (across grade levels) and horizontally (across subject areas). And so let us examine each direction in turn to consider how inquiry and argument might be fostered in a broader curricular context with multiple objectives. Moreover, the goal is not simply to make it all fit, but to make it fit well.

\section{References}

[1] A. Jackson and G. Davis, Turning points 2000: Educating adolescents in the21st century, New York: Teachers College Press, 2000, pp. 11.

[2] R. Murnane and F. Levy, Teaching the new basic skills, New York: Free Press, 1996.

[3] A. Brown, "Transforming schools into communities of thinking and learning about serious matters", American Psychologist, pp.52, 399-413, 1997.

[4] R. Siegler, "Microgenetic studies of learning", in Handbook of child psychology, Vol. 2, D. Kuhn and R. Siegler, Eds. Hoboken, NJ: Wiley, 2006.

[5] D. Kuhn and S. Pearsall, "Relations between metastrategic knowledge and strategic performance", Cognitive Development, Vol. 13, pp. 227247, 1998.

[6] M. Billig, Arguing and thinking: A rhetorical approach to social psychology, Cambridge: Cambridge University Press, 1987. 